\title{
Microchip Coulter particle counter
}

\author{
Larsen, Ulrik Darling; Blankenstein, Gert; Branebjerg, J.
}

Published in:

Solid State Sensors and Actuators, 1997. TRANSDUCERS '97 Chicago., 1997 International Conference on

Link to article, DOI:

10.1109/SENSOR.1997.635479

Publication date:

1997

Document Version

Publisher's PDF, also known as Version of record

Link back to DTU Orbit

Citation $(A P A)$ :

Larsen, U. D., Blankenstein, G., \& Branebjerg, J. (1997). Microchip Coulter particle counter. In Solid State Sensors and Actuators, 1997. TRANSDUCERS '97 Chicago., 1997 International Conference on (Vol. 2, pp. 1319-1322). IEEE. https://doi.org/10.1109/SENSOR.1997.635479

\section{General rights}

Copyright and moral rights for the publications made accessible in the public portal are retained by the authors and/or other copyright owners and it is a condition of accessing publications that users recognise and abide by the legal requirements associated with these rights.

- Users may download and print one copy of any publication from the public portal for the purpose of private study or research.

- You may not further distribute the material or use it for any profit-making activity or commercial gain

- You may freely distribute the URL identifying the publication in the public portal 


\title{
Microchip Coulter Particle Counter
}

\author{
Ulrik D. Larsen ${ }^{*}$, Gert Blankenstein ${ }^{*}$, Jens Branebjerg ${ }^{* *}$ \\ * Mikroelektronik Centret, Technical University of Denmark \\ Bldg.345e, DK-2800 Lyngby, Denmark, ud1@mic.dtu.dk \\ Danfoss A/S, 6430 Nordborg, Denmark
}

\section{SUMMARY}

This paper presents a micro device employing the Coulter principle for counting and sizing of living cells and particles in liquid suspension. The microchip Coulter Particle Counter $(\mu \mathrm{CPC})$ has been employed into a planar silicon structure covered with glass, which enables detailed observation during operation possible. By sheathing of a non-conductive liquid on either side of an electrolyte, it is possible to optimize the sensitivity to a specific cell-size dynamically.

A method for measuring the relative flow-rates between liquid phases with different conductivity is presented. The method utilizes the laminar flow and short contact time of liquids in microchannels. As a result, the width of the liquids can be controlled without knowing the actual flow rates.

The $\mu$ CPC have been fabricated by standard microfabrication techniques, including RIE, wet silicon etching, metalization and anodic bonding. The manufacturing is compatible with the fabrication of many different devices such as particle sorters and mixers.

Keywords: Particle counting, cell handling, flow sensor

\section{INTRODUCTION}

Coulter counting or sizing is a well established technique to people working in the field of medical diagnostics and research of living cells[1]. In the original Coulter particle counter [2] the particles are injected into an electrolyte and hydrodynamically focused into a single cell stream (figure 1). The flow of particles and sheathed electrolyte is passed through a small orifice in a plate separating two electrically isolated chambers. When a cell passes the orifice, the resistivity measured in the electrolyte from one side of the orifice to the other rises, due to the volume displacement of the electrolyte caused by the cell. The recorded signal from the resistivity measurement will show a transient signal for each passing cell. It is possible to use the recorded signal to count the cells and, from the height and area of the pulses to determine the size of the individual cells [1][3].

The principle used in the microchip Coulter Particle Counter $(\mu \mathrm{CPC})$ is similar to the conventional Coulter counter. However, a few modifications have been introduced in order to adapt the principle into a planar microchannel system, and to improve the sensitivity and reduce clogging of particles. The $\mu \mathrm{CPC}$ is part of a concept for biochemical analysis (presented at the 2nd international symposium on $\mu$ TAS'96 [4]). This concept includes a wide range of different components such as cell sorters[5] and mixers, that have all been fabricated with a simple, single wafer process.

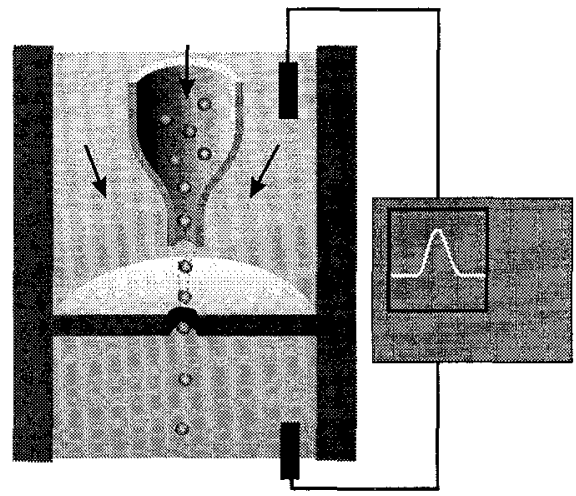

Figure 1: Drawing showing the traditional Coulter principle.

\section{ELECTROLYTIC CONDUCTIVITY}

The measurements are carried out by measuring the change in resistance of an electrolyte with a known conductivity $\kappa$. The conductivity of a solution depends on the number and type of ions present and thus on the molar concentration $\mathrm{c}$. The molar conductivity is defined as:

$$
\Lambda_{m}=\frac{\kappa}{c}
$$


A typical strong electrolyte is $\mathrm{KCl}$. The molar conductivity of $0.100 \mathrm{M} \mathrm{KCl} \mathrm{(aq)} \mathrm{at} 298 \mathrm{~K}$ is $129 \mathrm{~S}$ $\mathrm{cm}^{2} \mathrm{~mol}^{-1}$. The measured resistance in a channel with electrolyte depends both upon the conductivity and the geometry. If the cross-sectional area is constant the resistance is given by:

$$
R=\frac{1}{c \cdot \Lambda_{m}} \cdot \frac{l}{A}
$$

where $A$ is the area and $l$ the length.

If the resistance of the electrolyte in the microchannel and orifice is roughly calculated from this relation the $\mu \mathrm{CPC}$ would have an overall resistance $\left(R_{0}\right)$ in the range of 50-100 $\mathrm{k} \Omega$. Provided that the cells or particles have a much lover conductivity than the electrolyte (suggesting that they may be considered non-conducting) the change in resistance due to a single passing cell $(\Delta R)$ may be estimated. In the presented design the ratio $R_{0} / \Delta R$ would be $\sim 10^{4}$ depending on the device size, design, cell size and setup. Consequently, the measurements would be very sensitive and improvements of this ration might be necessary. The section on functionality discusses a few methods that could be used to improvement of the $\mu \mathrm{CPC}$.

\section{flow-ratio measurements}

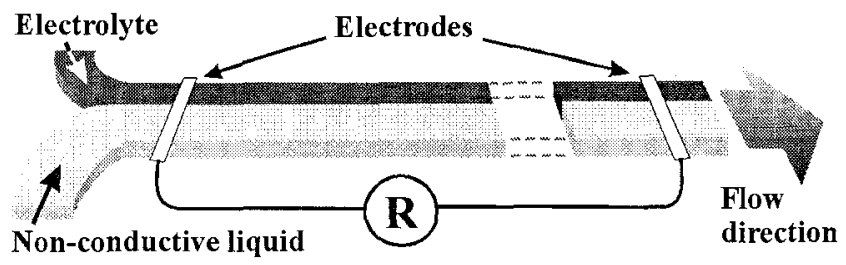

Figure 2. Laminated electrolyte and non-conductive liquid with electrodes for resistivity measurements.

When having two liquids of different conductivity flowing in one microchannel the total resistivity in a fixed length of the microchannel varies depending on the relative flowrates of the two flows. In the $\mu \mathrm{CPC}$ the outer sheath flow has very low conductivity and the electrolyte has high conductivity. The relative flows rates can be determined by measuring the variations of the total resistance. This enables in-situ measurements and control of the flow in the $\mu$ CPC. In general this technique can be used in microsystems for determination of the relative flowrate of two laminated liquid flows (figure 2). Figure 3 shows the measured total resistivity in a liquid channel of rectangular cross-section containing de-ionized water with varying flow rates of the two liquids. The results are plotted together with a $1 / \mathrm{x}$-fit which would be the expected correlation due to (2) when the length and depth is fixed and the flow profile of the two liquids do not change.

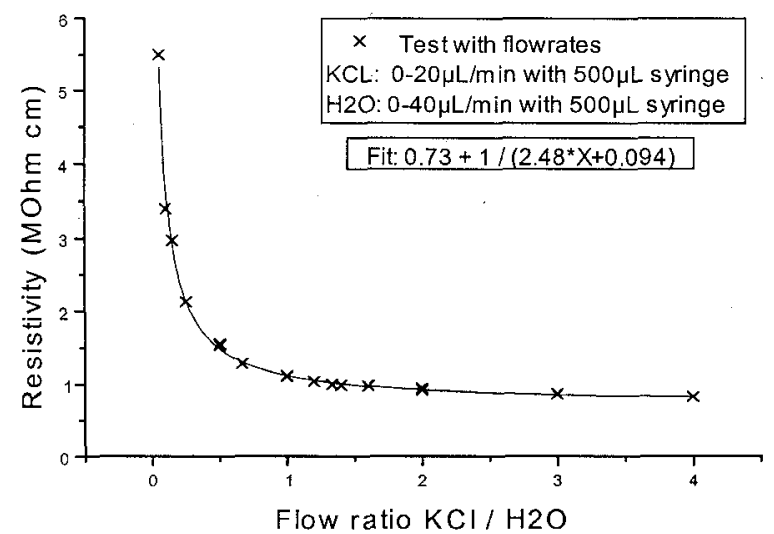

Figure 3. Resistance measured over the flow chip with conductive and non-conductive fluids. The resistance changes due to the relative flowrate of $\mathrm{KCl}$ and $\mathrm{DI}-\mathrm{H}_{2} \mathrm{O}$.

\section{FUNCTIONALITY}

As mentioned the $\mu \mathrm{CPC}$ is based on the original Coulter principle with a few modifications. The sample containing cells in suspension is injected through an inlet and into a wide channel (see figure 4 and 5). On each side of the sample inlet, an inlet has been placed for the sheathing of the electrolyte. On the outer faces of the electrolyte-inlets another inlet has been placed for introduction of a nonconductive liquid. The sample, which is a cellcontaining electrolyte is hydrodynamically focused into a single cell stream by the two sheathed electrolyte flows. The electrolytes and sample zones can be further focused to a specific width by the sheathed non-conductive liquid. The two fold sheathed flow passes through an orifice in the wide channel. It is not the width of the orifice but the width of the three conducting flows that determines the sensitivity of the $\mu \mathrm{CPC}$. Consequently, the width of the conducting flows can be scaled to the 


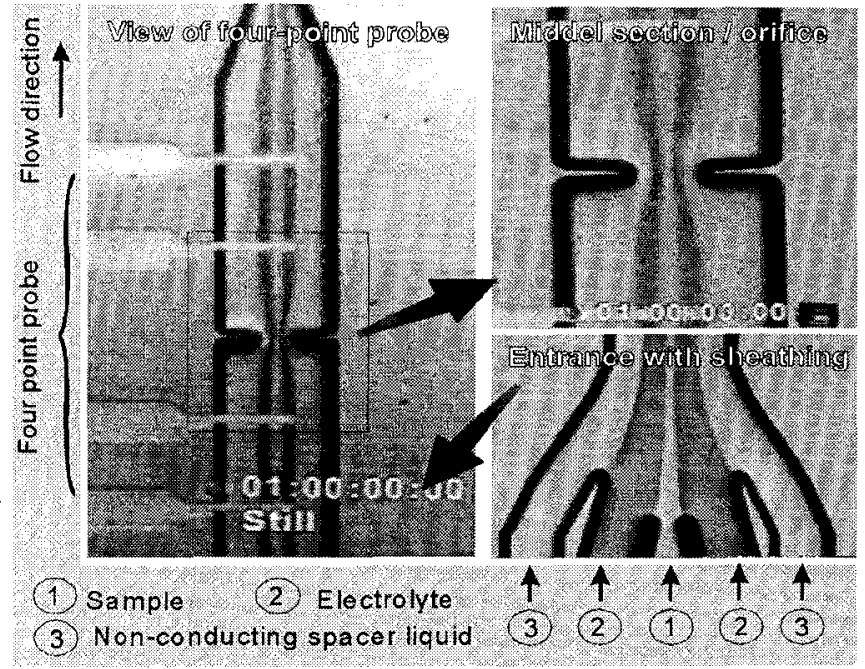

Figure 4. Videoprint of the $\mu C P C$ with liquids for testing. The picture to the left shows the channel with the orifice in the center. The sample and liquid are clear and the electrolyte used for hydrodynamic focusing is colored with phenole-red. The pictures to the right are close-ups of the sheathing- and orifice section. No mixing is visible!

size of a desired cell type. For hydrodynamic focusing in the vertical axis an inlet has been placed in the bottom of the channel in some of the constructed devices (see figure 5). Focusing in the vertical direction may prevent that cells are placed 'on top' of each other, which would lead to strange results.
Another feature is an integrated four-point electrode arrangement, which could be used to reduce the influence of variations in the electrode/liquid contacts. The $\mu \mathrm{CPC}$ have been fabricated with varying orifice size and with- and without the possibility of the additional non-conductive liquid and vertical hydrodynamic focusing.

\section{FABRICATION}

For the fabrication of the $\mu \mathrm{CPC}$ we have used four inch, $350 \mu \mathrm{m}$ thick, $<100>$ silicon wafers. An oxide layer of $1.5 \mu \mathrm{m}$ have been patterned with a mask containing the channel layout, a $2.6 \mu \mathrm{m}$ photoresist was spun on top of the oxide and patterned with a mask defining the inlets (fig.6a). The two step oxide and photoresist mask was used for etching a two step structure with vertical walls by reactive ion etching (RIE) in a $\mathrm{SF}_{6} / \mathrm{O}_{2}$ plasma (fig.6b). The holes were initially etched down to $22 \mu \mathrm{m}$, the photoresist mask was stripped and the etching of both channels and inlets was continued down to a depth of $50 \mu \mathrm{m}$. After a cleaning process a $1.8 \mu \mathrm{m} \mathrm{SiO}_{2}$ was patterned on the backside for accessing the inlets (fig.6c). The etching was carried out in $\mathrm{KOH}$ at $80^{\circ} \mathrm{C}$ and stopped when all the inlet holes were clearly visible from the backside (fig.6d). Finally a glass wafer with gold electrodes were fabricated and anodically bonded to the silicon wafer (fig.6e).

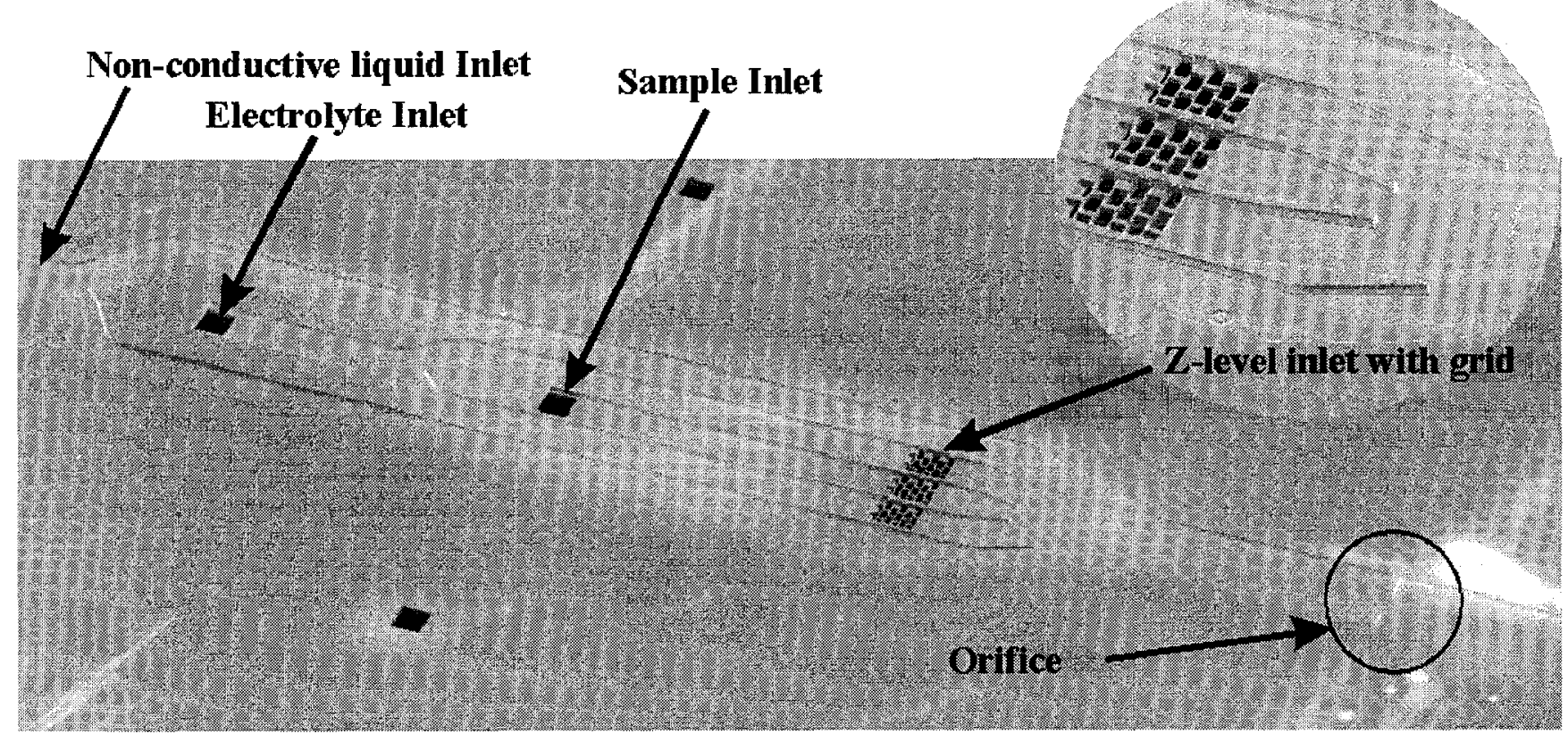

Figure 5. Etched channels in the silicon surface. To the left the inlet for vertical adjustment is visible. 
4C1.05

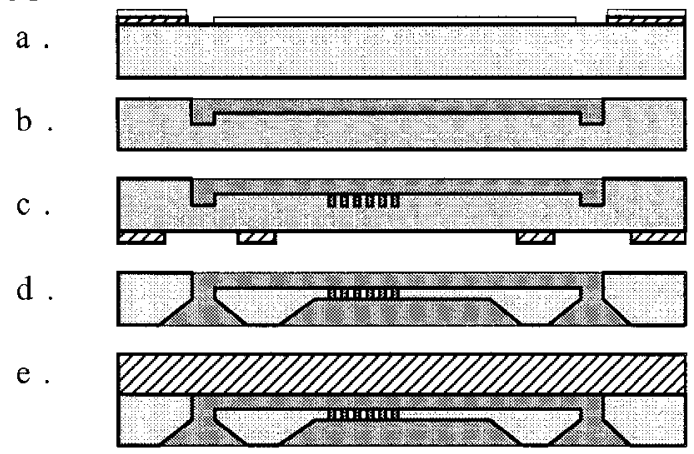

Figure 6. Fabrication sequence for the $\mu C P C$.

\section{EXPERIMENTS}

Our experiments with liquids containing particles in a microchannel system shows that clogging effects can be drastically reduced due to hydrodynamic focusing the electrolyte/sample flow by the nonconductive sheathed flow.

The flow-ratio-meter measurements were carried out by pumping liquids with syringe-pumps into the system, which makes it possible to control the sheathing very accurately.

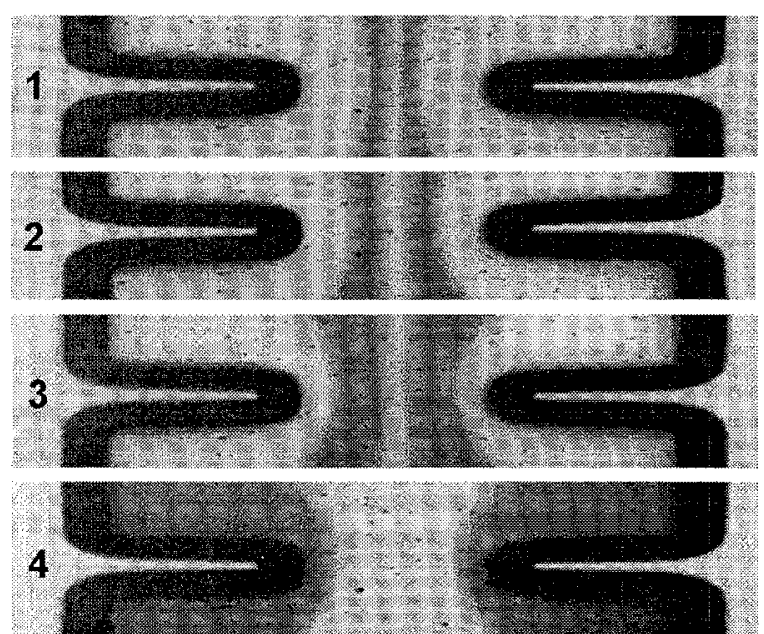

Figure 7. Videoprints of 4 situations: 1) Low coreand electrolyte flowrates. 2) Almost matching flowrates. 3) High electrolyte flowrate. 4) No liquid.

During the tests the $\mu \mathrm{CPC}$ was observed through a microscope with a video camera attached. On the videoprints in figure 7 we see that the sheathing of the inner core (clear) and electrolyte (dark) can be individually controlled to a specific width. The $\mu \mathrm{CPC}$ have been tested with latex beads and the signal was carefully amplified. However, reproducible measurements were not possible because of major damages to the electrodes in the areas exposed to the liquid. This circumstance suggests that either another electrode material should be used or some enhancement of the adhesion should be done.

\section{CONCLUSION}

A Microchip Coulter Particle Counter have been fabricated in a planar silicon structure. First tests shows that sheathing of liquids can be accurately controlled in microsystems which gives rise to a simple method for improvement of the sensitivity range of the Coulter principle. Furthermore clogging can be reduced when the cells are kept in a the core of a coaxial flow. Experiments shows that sheathing of liquids with different conductivity allows the implementation of an elegant in-situ flow-ratio-measurement. The evaluation of our design is still inconclusive and we have some improvements in mind.

\section{ACKNOWLEDGE}

The authors would like to thank S. Østergård for assistance with experiments and $\mathrm{K}$. Hoppe and $\mathrm{O}$. Leistiko for constructive ideas.

\section{REFERENCES}

[1] J.P. Freyer, M.E. Wilder, P.L. Schor, J. Coulter, M.R. Raju, "A Simple Electronic Volume Cell Sorter for Clonogenicity Assays", Cytometry 10:273-281, Alan R. Liss, Inc., 1989

[2] W.H. Coulter: "High speed automatic blood cell counter and cell size analyzer", Proc. Natl. El. Conf.12 (1956), pp.1034-1040

[3] V. Kachel, "Electrical Resistance Pulse Sizing: Coulter Sizing", Flow Cytometry and Sorting, 2. ed., pp.45-80,1990 Wiley-Liss, Inc

[4] U.D. Larsen, G. Blankenstein, J. Branebjerg, "A Novel Design in Chemical and Biochemical Liquid Analysis Systems.", proc. 2nd Int. Symp. $\mu$ TAS96, Basel 19-22 nov. $1996, \mathrm{pp} .113-115$

[5] G. Blankenstein, L. Scampavia, J. Branebjerg, U.D. Larsen, J. Ruzicka, "Flow Switch for Analyte Injection and Cell/Particle Sorting", proc. 2nd Int. Symp. MTAS96, Basel 19-22 nov. 1996 , pp.82-84 